\title{
TUMOUR NECROSIS FACTOR - ALPHA MEDIATED MECHANISMS OF COGNITIVE DYSFUNCTION
}

Background: Tumour necrosis factor - alpha (TNF-a) is a pro-inflammatory cytokine that combines a plethora of activities in the early stages of an immune response. TNF- $a$ has gained increasing importance given TNF- $a$ upregulation in multiple brain pathologies like neuropsychiatric conditions such as depression, schizophrenia, as well as neuroinflammatory disorder like multiple sclerosis (MS).

Aim: The aim of this review is to critically analyse neurobiological, immunological and molecular mechanisms through which TNF-a influences the development of cognitive dysfunction.

Principal findings/results: The review presents several lines of original research showing that the immunological properties ofTNF-a exacerbate inflammatory responses in the central nervous system such as microglial and endothelia activation, lymphocytic and monocytic infiltration and the expression of downstream pro-inflammatory cytokines and apoptotic factors. Depression, schizophrenia, and MS all manifest symptoms of activated immune response along with cognitive dysfunction, with TNF-a overexpression as a central clinical feature common to these disorders. Furthermore, TNF- $a$ acts negatively on neuroplasticity and the molecular mechanisms of memory and learning (i.e., long-term potentiation and long-term depression). TNF- $a$ also exerts influence over the production of neurotrophins (i.e., nerve growth factor and brain-derived neurotrophic factor), neurogenesis, and dendritic branching.

Conclusions/significance: This review outlines that TNF- $\alpha$ and its receptors have a substantial yet underappreciated influence on the development and progression of neuropsychiatric symptoms across several disease entities. An improved understanding of these underlying mechanisms may help develop novel therapeutic targets in the form of drugs specifically targeting downstream products of TNF-a activation within the central nervous system.

Keywords

- Tumour necrosis factor alpha $\cdot$ Cytokines $\cdot$ Neuropsychiatry $\cdot$ Neuroinflammation $•$ Depression $•$ Neuroplasticity $\cdot$ Neurotrophins

(c) Versita Sp. z o.o.

\section{Introduction}

Mental and neurological disorders like schizophrenia and depression constitute $13 \%$ of the global disease burden, quickly surpassing the threat by cardiovascular disorders and cancer [1]. A common link between neuropsychiatric conditions such as major depressive disorder (MDD), and schizophrenia, neuroinflammatory disorder like multiple sclerosis (MS) and rheumatoid arthritis (RA), which manifest neuropsychiatric symptoms [2-4], is the presence of exaggerated immune system activation both peripherally and within the central nervous system (CNS) [5-7]. In the periphery, patients with MDD have impairments in cellular immunity (reduced natural killer cell activity) [8], as well as increased expression of pro-inflammatory cytokines like interleukins IL-1 $\beta$, IL-6, tumour necrosis factor alpha (TNF-a) and chemokine IL-8 [9]. This

*E-mail:Bernhard.Baune@Adelaide.edu.au peripheral immune activation is associated with stimulation of resident astrocytes, microglia and neurons within the CNS, which produce inflammatory cytokines [10-12]. Indeed, depression is now thought to be the result of an increased production of pro-inflammatory cytokines that is caused by external or internal stressors, with this known as the cytokine theory of depression [9]. This leads to a low grade chronic inflammatory state that alters neurotransmitter metabolism, neuroendocrine function, promotes oxidative and nitrosative stress and reduces neuroplasticity resulting in the typical symptoms of melancholia, anhedonia, psychomotor slowing, decreased appetite and fatigue [9].

As in MDD, reports of peripheral and central immune activation have been documented in schizophrenia. Elevated serum and/or plasma levels of pro-inflammatory factors like prostaglandin E2 $\left(\mathrm{PGE}_{2}\right)$ [13], C-reactive protein

\author{
Bernhard T Baune ${ }^{1, *, *}$, \\ Marie-Lou Camara ${ }^{1,4, \#,}$ \\ Harris Eyre ${ }^{1,4}$, \\ Catharine Jawahar ${ }^{1}$ \\ Helen Anscomb ${ }^{2}$ \\ Heinrich Körner
}

'Discipline of Psychiatry, School of Medicine, University of Adelaide, Adelaide, SA, Australia

2 Discipline of Anatomy, School of Medicine, James Cook University, QLD, Australia

${ }^{3}$ Cellular Immunology Laboratory, Menzies Research Institute Tasmania, Hobart, Tasmania, Australia

${ }^{4}$ Psychiatry and Psychiatric Neuroscience, School of Medicine, James Cook University QLD, Australia

"These authors should be regarded as joint first authors as they have contributed equally to the manuscript.

Received 26 March 2012 accepted 23 June 2012
(CRP) [14], IL-1 $\beta$ and TNF- $\alpha$ [15] have been found in schizophrenic individuals. Furthermore, high microglial activation in the brain of schizophrenic patients has been reported in postmortem studies $[16,17]$. This has been verified by positron emission tomography (PET) studies in patients, particularly in the medial temporal cortex $[18,19]$. These activated microglia then release TNF- $\alpha$ and IL-6 [6] contributing to the diseased state of the brain in schizophrenia. The presence of an exaggerated immune response and downstream signalling of pro-inflammatory cytokines in MDD and schizophrenia are thought to be the underlying causes of the impairments in learning and memory, as well as increased anxiety and sleep disturbances $[9,20]$ seen in these psychiatric illnesses. Indeed, neurodegeneration induced by this neuroinflammatory state is seen as a reduction in hippocampal volume in depressed patients [21], which is associated with mild 
to moderate impairments in cognitive performance compared to healthy norms.

The relationship between inflammation and neuropsychiatric symptoms such as cognitive dysfunction can also be seen in neuroinflammatory condition like MS and systemic autoimmune disorder like RA frequently presenting with neuropsychiatric symptoms. MS patients often suffer from cognitive dysfunction and depression [3], with the presence of an activated immune system, especially pro-inflammatory cytokines thought to be the cause of the neuropsychiatric symptoms observed [7]. Indeed this supposition has been demonstrated in animal models [22], where experimental autoimmune encephalomyelitis (EAE) leads to a reduction in the volume of the $C A 1$ region of the hippocampus, primarily due to activated microglia and infiltrating macrophages that release pro-inflammatory cytokines like TNF-a $[22,23]$. This glial activation leads to decrease in volume of the CA1 region of the hippocampus, along with decrease in the number of $\gamma$-aminobutyric acid (GABAergic) interneurons and increased number of TUNEL-positive cells (apoptotic cells) in the hippocampus leading to the cognitive dysfunction observed in MS [22].

RA, though a systemic autoimmune disorder, often displays with its own set of neuropsychiatric symptoms. RA patients exhibit deficits in cognitive function (learning and memory) [24] as well as increased anxiety [25] and depression [26]. The cognitive deficits observed in RA patients could be attributed to the high levels of pro-inflammatory cytokine TNF- $a$ in serum $[25,27]$. Therefore these high levels of TNF- $a$ may interact with the CNS to impair the expression of neurotrophins like nerve growth factor (NGF) resulting in a loss of neurogenesis and synaptic function [27].

These findings demonstrate as an overarching theme that immune system activation, particularly release of proinflammatory cytokines, can affect core functions of the CNS like neuroplasticity and cognition [28]. The significance in studying the neurobiological functions of TNF-a specifically stem from its unique influence in mediating synaptic scaling, especially a-amino-3-hydroxy- 5-methyl-4-isoxazolepropionic acid receptors (AMPAR) dependent plasticity [28] as well as its effects of development of hippocampal structures [29]. The pro-inflammatory cytokine TNF- $a$ is constitutively expressed in the CNS, and has been shown to exert physiological neuroprotective and neurodegenerative effects, depending on whether the TNF- $\mathrm{a}-\mathrm{R} 1$ or TNF-a-R2 receptor is activated. Signalling through the TNF-a-R1 pathway, initiates the activation of caspases leading to apoptosis, due to the presence of a cytoplasmic 'death domain'. In contrast, activation of TNF- $a-R 2$ promotes cell survival through inhibition of caspase activation.

Thus, although increased levels of TNF- $a$ may underlie the neuropsychiatric symptoms of a number of diseases [30], in physiologically unchallenged conditions, we have shown in a murine model, that during early stages of development basal levels of TNF- $a$ are required in the CNS for memory and learning [31]. These neuroprotective effects of TNF- $a$ are mediated by its influence on neurotrophin production [29] as well as on its ability to influence synaptic scaling [32]. Therefore the aim of this review is to determine the neurobiology of TNF-a within the CNS under normal and pathological conditions and its contribution specifically to cognitive dysfunction as a key symptom of various conditions. A more detailed knowledge of the cellular mechanisms by which TNF- $a$ contributes to the development and progression of neuropsychiatric symptoms, particularly the mechanisms subserving cognition, could be instrumental in developing effective therapeutic strategies.

\section{Methodology}

The literature search for this review was carried out according to the guidelines specified by PRISMA (Preferred reporting items for systematic reviews and meta-analyses) [33]. The PRISMA statement consists of a checklist of 27 items of which 12 are specific to the methodology of writing a review and metaanalysis. The methodology for this study was carried out by using the following items from the list: describing the information sources and search strategy using keywords and limits, as well as the screening and eligibility criteria. Other items of the PRISMA list, pertaining to statistical summary measures and data analyses were not relevant to this review and applied to the writing of a meta-analysis. As such these items were excluded in the researching of this systematic review. No ethical approval was required for writing this review.

\section{Search Strategy}

For this systematic review, databases PubMed and ScienceDirect were searched with various permutations of the following keywords: CNS, cognition, immune system, neurogenesis, pro-inflammatory cytokines, brain derived neurotrophic factor, cognitive, hippocampus, memory, learning, brain, neurotrophin, plasticity, long-term potentiation (LTP), longterm depression (LTD), TNF- $a$, TNF-a receptors, $p 55, p 75$, nerve growth factor, neuropsychiatric disorders, schizophrenia, depression, stress, anti-TNF-a, synaptic scaling, neurogenesis, p38, c-Jun N-terminal kinase (JNK), mitogen activated protein kinase (MAPK), multiple sclerosis, rheumatoid arthritis.

\section{Selection}

Articles published online and in English between January 1990 and October 2011 were included. In order to elaborate the context of the research, some historical references were also made. Initial searches yielded a total of approximately 1000 articles. Approximately 500 articles were retrieved and studied after reviewing abstracts for relevance to this review. At this stage articles were excluded if they included anecdotal evidence, if full text copies could not be retrieved, or if original studies translated into English could not be retrieved. Articles were also obtained from an examination of the reference lists of several reviews on each sub-topic. In total 153 articles were used in the writing of this review. Figure 1 (Adapted from PRISMA [33]) depicts this strategy (Figure 1).

\section{Interrelationship between immune system and CNS function}

A few decades ago the CNS was regarded as a region devoid of immune reactions $[34,35]$. Thus, the CNS, which includes the brain and spinal cord, was believed to be a site of 
Initial PubMed and
SciencDirect Library

searches $(n \sim 1000)$

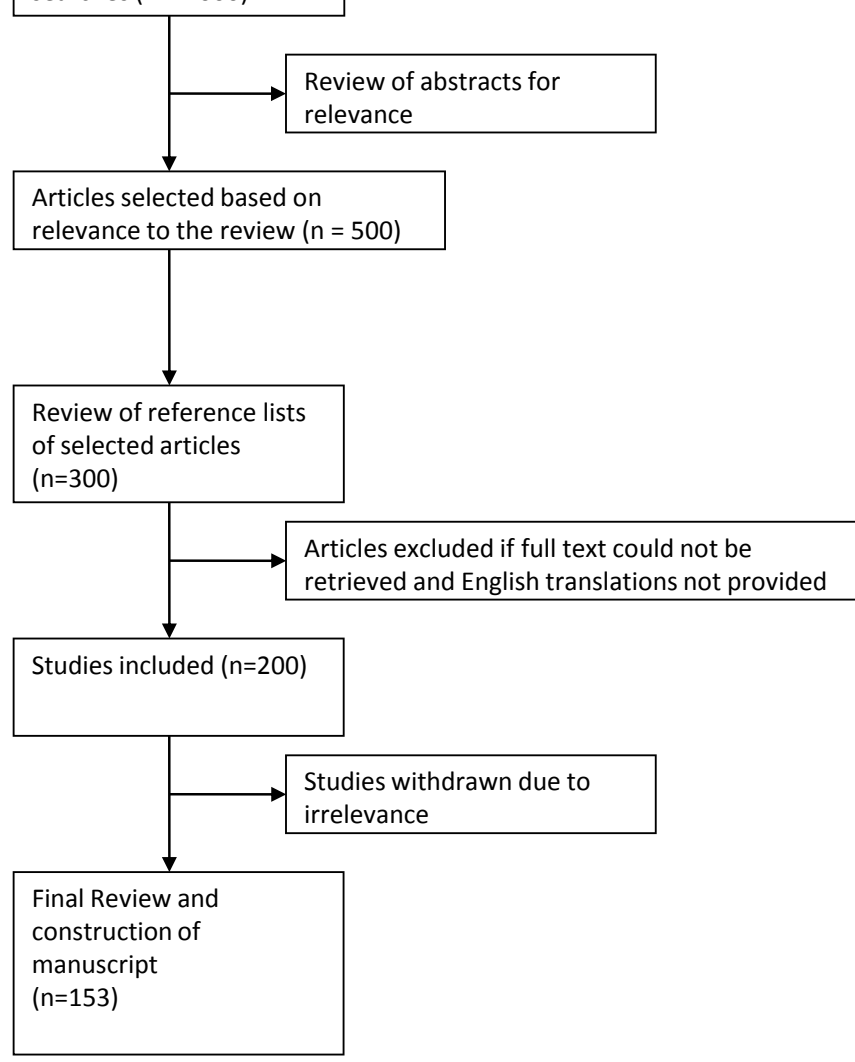

Figure 1. Study inclusion flowchart. Legend: Flowchart adapted as per PRISMA guidelines, details the methodology of collecting data in the writing of this article.

"immune privilege". However this claim has now been significantly modified and redefined to suggest that the CNS is in fact an area of selective immune reactivity that results from active processes [36,37].

The immune system plays a very complex role in the maintenance of the CNS. Immune system sustains homeostatic equilibrium of the various structures of the brain and constantly surveys the brain ensuring neuroprotection [38]. Furthermore, it also plays a crucial nonimmune role in the neurodevelopment by acting on processes such as neurogenesis, neuronal migration and synaptic plasticity (for reviews see $[39,40])$. The blood-brain barrier (BBB) of the CNS is the main system that controls leukocyte trafficking from the periphery into the brain $[41,42]$ while the epithelial bloodcerebrospinal fluid barrier (BCSFB) controls the influx of lymphocytes to brain parenchyma. It is through this interaction between the BBB and the BCSFB that immune cells enter and patrol the CNS [43].

Threat by external stimulus in the form of injury, infection or stress may affect the balance between CNS and the immune system. This results in the trafficking of $T$ and $B$ cells leading to downstream activation and subsequent entry of pro-inflammatory cytokines like TNF- $a$ into the brain via the BBB [44-48]. The BBB has cytokine binding sites that either alter intracellular function (receptors) or convey the cytokines across the BBB (transporters) [42]. Pro-inflammatory cytokines trigger the expression and activation of other inflammatory factors including other cytokines, chemokines and reactive oxygen species, that leads to necrotic and apoptotic neural injury $[49,50]$. Of these cytokines, TNF-a in particular is shown to be upregulated in CNS inflammatory conditions that involve BBB disruption [51]. Both TNF-a receptors, p55 and p75 are present on the endothelial cells of the BBB and function like transporters [48]. Additionally, TNF-a suppresses the expression of claudins (Cldn), particularly Cldn5, an essential molecular component of tight junctions [52,53].

Apart from peripheral inflammatory cells that traverse the BBB, the CNS has its own immune system. Microglia are the resident immune cells of the CNS [54]. Resting microglia or those that are activated by an adaptive immune response of Th1 and Th2 cytokines IL-4 and interferon $\gamma$ (IFN- $\gamma$ ) promote neurogenesis [55]. Additionally resting microglia are also thought to induce neurogenesis through MAPK signalling pathways [56]. Infections or trauma on the other hand cause microglia to be differentially activated and release proinflammatory cytokines like IL-6, TNF- $a$ and IL$1 \beta$. Activated microglia present dual functions -1) The elimination of damaged neurons and 2) Activation of immune system, by downstream signalling of pro-inflammatory cytokines [11]. Of the pro-inflammatory cytokines released by microglia, TNF- $a$ is thought to be the main factor behind $B B B$ dysfunction resulting in a feedback loop of continual inflammation between the periphery and the CNS [51].

Regardless of the primary source of TNF- $a$ in the brain, the symptoms that it produces in acute inflammatory conditions are deleterious (Figure 2). Animal studies have linked TNF-a overexpression to cerebral malaria [57], progression of septic shock syndrome [58], formation of sickness behaviour [59], thrombosis and tissue necrosis [60]. However, despite these negative effects, under physiologically unchallenged conditions TNF-a exerts beneficial actions. In normal conditions it promotes and regulates neurogenesis [61], plays a role in hippocampal development [29], and is essential to learning and memory formation [28,62] (Figure 2, Table 1). This complex and divergent role of TNF- $\alpha$ is mediated 
by its signalling through its main receptors, TNF- $a-R 1$ and TNF-a-R2. TNF-a can function both in a neuroprotective manner as well as in a neurodegenerative manner based on its expression and the receptor through which it signals [63]. The following sections detail the neurobiology of TNF- $a$ from expression to signalling patterns in physiologically unchallenged as well as pathological conditions.

Table 1. Studies demonstrating TNF-a required for normal cognitive function.

\begin{tabular}{|c|c|c|c|}
\hline Model & Analysis & Results & References \\
\hline $\begin{array}{l}\text { C57/BL6 mice } \\
\text { and TNF -/- mice. }\end{array}$ & $\begin{array}{l}\text { ELISA: Serum protein analysis of } \\
\text { NGF, BDNF, TNF-a } \\
\text { IHC: Dendritic tree of hippocampal neurons } \\
\text { IHC: staining for BDNF and NGF in medial hippocampal } \\
\text { slices } \\
\text { Cognitive testing: } \\
\text { Morris water maze } \\
\text { Open field test } \\
\text { Elevated plus maze } \\
\text { Hole board }\end{array}$ & $\begin{array}{l}\text { Associated with reduced BDNF levels and branching of } \\
\text { apical dendrites in CA1 and CA3 regions of hippocampus }\end{array}$ & [29] \\
\hline $\begin{array}{l}\text { C57/BL6 mice, } \\
\text { B6.TNF-/- mice, } \\
\text { B6.TNF-R1-/- } \\
\text { and B6.TNF-R2-/- mice }\end{array}$ & $\begin{array}{l}\text { Cognitive testing: } \\
\text { Novel object recognition } \\
\text { Open field test; Barnes maze } \\
\text { Gene expression: PCR of brain stem, hippocampus, } \\
\text { cerebellum and frontal cortex. } \\
\text { CBA for IL-1 } \beta \text {, IL-6, IL-8, IL-10, IL-12p70 }\end{array}$ & $\begin{array}{l}\text { Basal levels of TNF under non-inflammatory conditions } \\
\text { are required for normal learning and memory }\end{array}$ & [31] \\
\hline $\begin{array}{l}\text { TNF-/- mice, } \\
\text { C57/BL6 mice }\end{array}$ & $\begin{array}{l}\text { Cognitive testing: } \\
\text { Barnes maze }\end{array}$ & $\begin{array}{l}\text { Absences of TNF with increasing age is protective of age- } \\
\text { related memory decline }\end{array}$ & [150] \\
\hline $\begin{array}{l}\text { TNF }-/- \text { mice } \\
\text { and C57/BL6 mice, } \\
\text { B6.TNF-R1-/- }\end{array}$ & Flow cytometry of spleen cells using FACSCalibur & $\begin{array}{l}\text { TNF is required for down regulation of } \mathrm{T} \text { cell responses } \\
\text { against myelin antigens in EAE }\end{array}$ & [68] \\
\hline
\end{tabular}

Legend: BDNF - brain-derived neurotrophic factor; NGF - nerve growth factor; ELISA - enzyme linked immunosorbent assay; IHC - immunohistochemistry; FACS - fluorescence activated cell sorting; MS - multiple sclerosis; PCR - polymerase chain reaction; EAE - experimental autoimmune encephalomyelitis; ICAM - intercellular adhesion molecule 1;VCAM - vascular cell adhesion protein 1; PBMC - peripheral blood mononuclear cell; BA 46 - Brodmann area 46; BA 24 - Brodmann area 24.

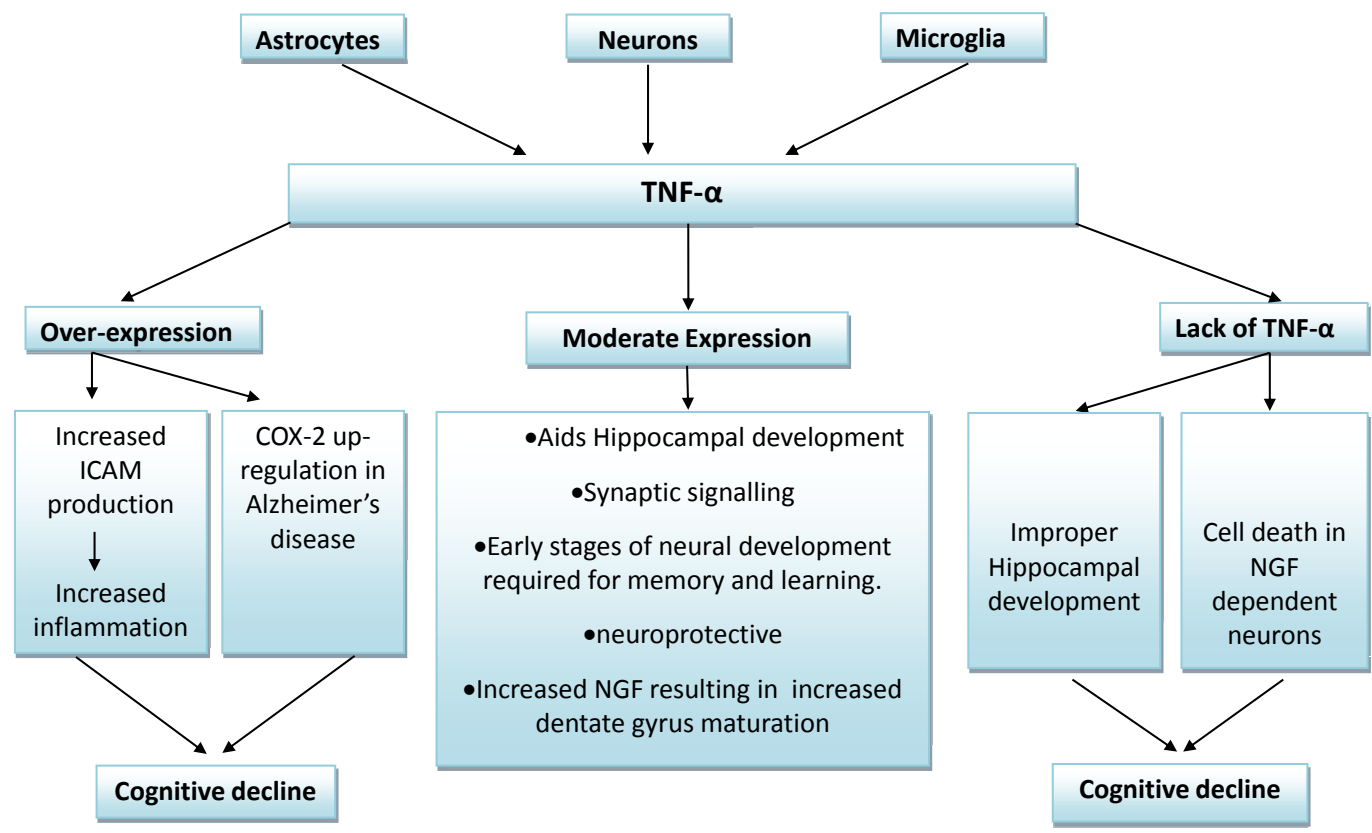

Figure 2. Illustration of the differential expression of TNF-a by astrocytes and microglia. Legend: The figure demonstrates how TNF-a, produced by astrocytes and microglia is required for cognition at moderate levels by aiding hippocampal development and synaptic signalling. While an overexpression of the protein causes increased intercellular cell adhesion molecule (ICAM) production resulting in cognitive decline. Similarly a lack of TNF-a causes death of nerve growth factor (NGF) dependent neurons and affects cognition. This shows that basal levels of TNF-a are required for memory and learning and a disruption in this causes cognitive dysfunction. 
Neurobiology of TNF-a in the CNS

Pro-inflammatory cytokine TNF- $a$ is a member of the TNF super family of ligands [64]. It is synthesized in its pro form as a monomeric type 2 transmembrane protein (tmTNF-a) and is inserted into the cell membrane and cleaved to its soluble form (solTNF-a) by a matrix metalloprotease TNF-a-converting enzyme (TACE/ADAM17) [65]. Both forms of TNF-a are biologically active and are produced in the CNS by astrocytes, microglia as well as neurons $[10,66,67]$.

TNF-a signals mainly through two receptors, TNF-a-R1 (TNFRSF1A/p55) and TNF- $a-R 2$ (TNFSFR1B/p75) [68]. Both receptors are expressed on a variety of cell types; TNF- $a-R 1$ is expressed by most cells while TNF- $a-R 2$ is expressed only by immune cells, endothelial cells and microglia [69]. The TNF-a receptors bind to both forms of TNF-a, however TNF$a-R 1$ has a higher affinity for solTNF-a, while TNF-a-R2 has a higher affinity for tmTNF-a [69].

\section{TNFa-R1 signalling pathway}

TNF- $\mathrm{a}-\mathrm{R} 1$ is characterised by the presence of a death domain (DD) that distinguishes it from TNF- $a-R 2$. The presence of the DD allows TNF-a-R1 to dissociate silencer of death domain (SODD) and subsequently activates TNF-a receptor associated death domain (TRADD) [70]. TRADD activation results in the recruitment and activation of three proteins, Fas-associated death domain (FADD), receptor interacting protein (RIP) and TNF-a receptor associated factor 2 (TRAF2) [71,72] each leading to different signalling cascades (Figure 3 ).

FADD activation leads to recruitment of caspase 8 resulting in activation of an apoptotic pathway [73]. TRAF2 activates a mitogen associated protein kinase kinase kinase (MAPKKK or MEKK3) to ultimately activate JNK and C-Jun. RIP activation is responsible for the activation of NF-KB pathway by activation of MEKK3, a mitogen kinase that degrades inhibitor of kappa B kinase (IKK) [70].

Extensive crosstalk occurs between these three pathways. The recruitment of the TRADD associated pathways results in further recruitment of cellular inhibitor of apoptosis 1 and 2 (CIAP 1,2$)$ resulting in downstream activation of JNK pathway $[74,75]$. Acute activation of JNK activation is cytoprotective, however chronic activation of the pathway leads to caspase dependent apoptosis [76].

$\mathrm{NF}-\mathrm{KB}$ is expressed in the cytoplasm and is maintained in its inactive form by inhibitor of kappa B (IKB). IKK on activation phosphorylate IKB allowing NF-KB to migrate to the nucleus to modulate transcription of genes involved in neuroprotective or neurodegenerative processes [77]. NF-KB also regulates genes involved in synaptic plasticity, spatial memory and cell proliferation (for review see [78]). It also protects cells from apoptosis but cross talk with the FADD pathway in chronic conditions results in caspase activation causing cleavage and degradation of RIP that is essential to NF-KB signalling [70]. This demonstrates a complex interaction between the downstream signalling pathways of TNF-a-R1 activated signalling.

\section{TNFa-R2 signalling pathway}

TNF- $a-R 2$ due to its presence on limited type of cells, demonstrates fewer biological effects than TNF- $a-R 1$ and does not induce caspase dependent apoptosis [69].TNF- $a-R 2$ is shown to activate TRAF-1 and TRAF-2 proteins resulting in NF-KB and CIAP activation respectively, thus showing overlapping effects with TNF- $\alpha-R 1$ [79]. Additionally this receptor also activates phosphatidylinositol 3-kinase-dependent NF-KB signalling that protects neurons from glutamate induced excitotoxicity, giving evidence to the neuroprotective effects that have been observed with TNF-a-R2 signalling [80] (Figure 3). Thus the conditions under which TNF-a is produced - normal physiological or pathological - will determine its subsequent binding to the appropriate receptor and dictate its neurobiological functions.

\section{TNF-a signalling and neuroplasticity}

The neurobiological effects of TNF- $a$ in the CNS extend from its ability to influence synaptic scaling as well as influence neurogenesis to neurotrophin production (Figure 4). Longterm potentiation and depression, the strengthening and weakening respectively of synaptic connections are a form of Hebbian plasticity and are believed to be the synaptic model of memory and learning processes [81].
Hebbian plasticity is maintained by regulating the strength of synaptic input and neuronal excitation. This is known as homeostatic synaptic plasticity or synaptic scaling and is defined by changes in surface expression of AMPAR at the synaptic junction (for review see [82]).

Glutamate is the main excitatory neurotransmitter and is required for memory formation, learning and synaptic plasticity. It mediates this through the action of its receptors AMPAR and $\mathrm{N}$-methyl-D-aspartate receptor (NMDAR) [32]. Additionally, glutamate can activate NF-KB in neurons [83]. Animal studies in vitro have shown that astrocytic released TNF- a causes trafficking of AMPAR, in primary cell cultures and hippocampal slices [84] by acting directly on neurons as well as by decreasing the expression of inhibitory GABA receptors [32]. Interestingly this effect on AMPAR seems to be specific to TNF-a and not other cytokines and is mediated through TNF- $a$ receptor, TNF- $a-R 1$ but not TNF- $a-R 2$ [32]. This interaction between TNF- $a$ and glutamate receptors denotes a possible role of TNF- $a$ in AMPAR-dependent LTP and LTD, the underlying mechanisms of learning and memory [28]. Furthermore TNF-a increases amplitude of miniature excitatory postsynaptic currents (mEPSC) and decreases miniature inhibitory postsynaptic currents (mIPSC) $[32,84]$. However, chronic increase in levels of TNF- $\alpha$, in pathological conditions, inhibits LTP in the CA1 region and dentate gyrus of the hippocampus [85]. TNF-a inhibits synaptic scaling through activation of NFKB pathways [62,86], JNK [87] and p38 MAPK pathway [86]. The p38 MAP kinase pathways is a signal transduction pathway that regulates inflammatory processes of cell death as well as playing a role in growth and differentiation ([88]; for review see [89]). These results demonstrate how chronic inflammation causes the neuroprotective effects of TNF-a to switch to neurodegenerative.

The influence of TNF- $a$ in the CNS further extends to neurotrophin production and expression. NGF, brain-derived neurotrophic factor (BDNF), neurotrophin-3 (NT-3), and neurotrophin-4 (NT-4) all derived from a common ancestral gene, are similar in sequence 


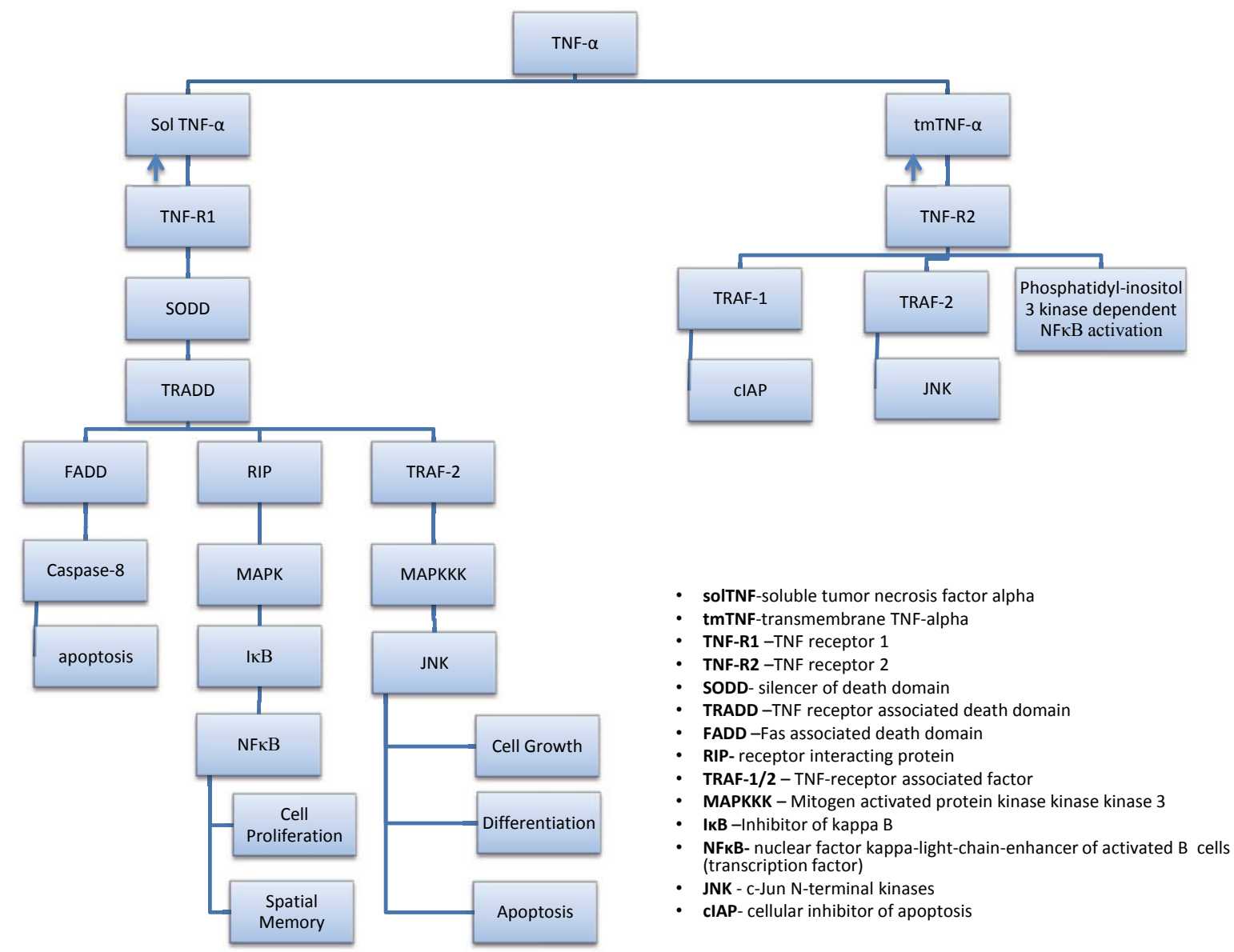

Figure 3. TNF-a signaling in the CNS. Legend:The figure shows the signal transduction pathway for TNF-a. TNF- $a$ acts via two different receptors TNF-a-R1 and TNF-a-R2 and exerts either positive or negative neurobiological processes depending on the downstream pathway.

and structure, and are therefore collectively named neurotrophins [90]. Neurotrophic factors are involved in growth, maintenance and differentiation of neurons [91]. They are important regulators of neural survival, development, function, and plasticity [92,93]. NGF and other neurotrophins are believed to be essential for survival and the regeneration of sensory and sympathetic neurons [94] as well as of injured neurons [91]. TNF-a has the ability to act in a positive or negative manner on neurotrophin synthesis in a dose-dependent manner [95].

NGF exerts its effects by binding to two receptors, the $\mathrm{p} 140^{\mathrm{TrkA}}$ receptor that is specific to NGF and the p75 ${ }^{\mathrm{NTR}}$ receptor that is common to all neurotrophins. The $p 75^{\text {NTR }}$ receptor is a member of the TNF receptor super family and can bind to the $\mathrm{p} 140^{\mathrm{TrkA}}$ receptor to enhance the responsiveness of NGF. In the absence of $\mathrm{p} 140^{\mathrm{TrkA}}, \mathrm{p} 75^{\mathrm{NTR}}$ can induce apoptosis. In the CNS, inflammation causes glial cells and immune cells to produce NGF [96]. The close association with TNF-a, glia, and neurons, led to the proposal of a positive feedback loop of NGF synthesis; NGF expression by glia could lead to the production of TNF, similarly TNF produced by neurons and glia could further activate other inflammatory cells to release NGF [97]. In the presence of NGF, TNF- $a$ activates TNF- $a-R 2$. However, in the absence of NGF, TNF-a-R1 is activated [97]. A study by Golan et al. (2004), a study by Golan et al. (2004), showed that in the absence of TNF-a (TNF- $\mathrm{a}-\mathrm{KO}$ mice), the expression of NGF was increased compared to WT mice [29]. Additionally this increase in the levels of NGF was accompanied with better hippocampal development characterised by higher cell density in the hilus of the dentate gyrus. This could mean that in the absence of TNF-a other pro-inflammatory cytokines could possibly activate microglia to produce NGF [29]. TNF- $a$ further influences the production of BDNF, a modulator of synaptic plasticity and neuronal morphology $[29,98]$. An in vitro study showed that astrocytic TNF-a causes BDNF levels to increase through activation of NF-KB transcription factor [98]. In support of this finding it was shown in mice that TNF-a deprivation in the hippocampus caused BDNF levels to be low resulting in decreased dendritic branching in the CA1 and CA3 region of the hippocampus leading to improper development of the hippocampus 


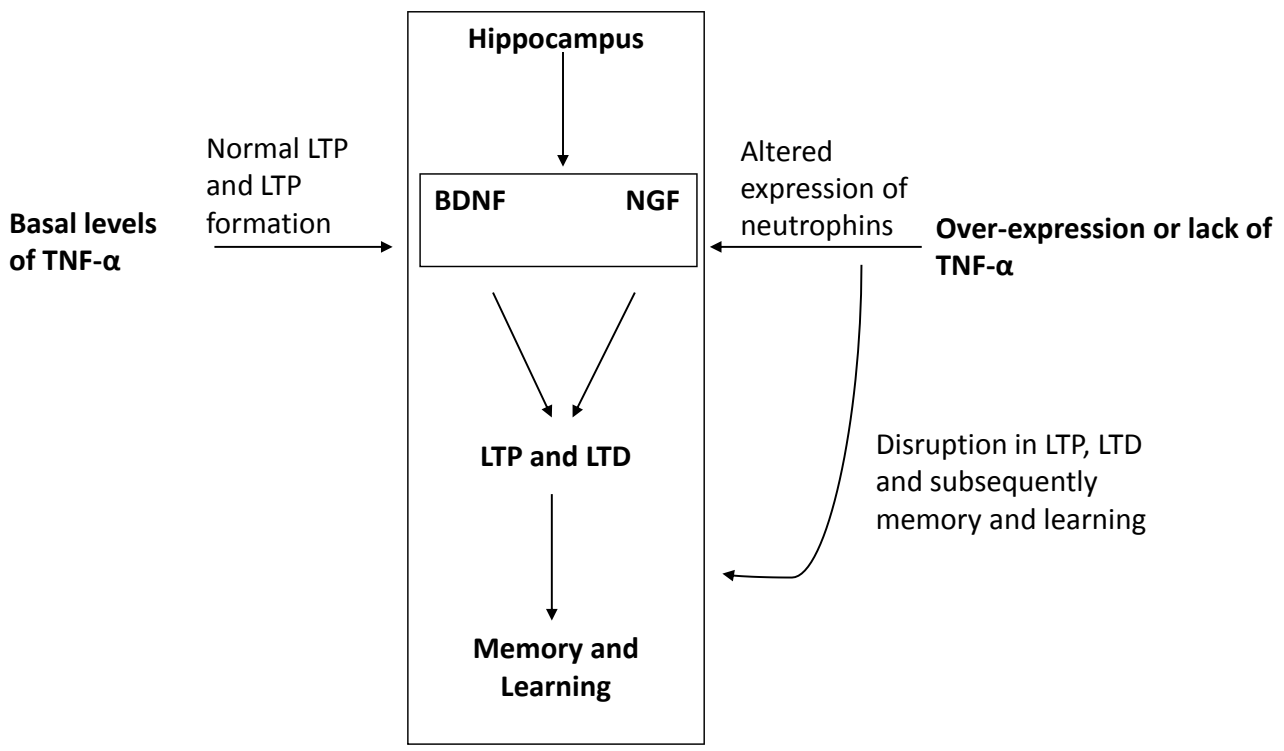

Figure 4. Role of TNF-a in neurotrophin production and hippocampal memory and learning. Legend: The figure shows how basal levels of TNF-a are required for the production of brain derived neurotrophic factor (BDNF) and nerve growth factor (NGF). BDNF and NGF in turn are required for long-term potentiation (LTP) and long-term depression (LTD), the molecular basis of memory and learning. An over-expression of TNF causes LTP and LTD to be altered, consequently altering memory and learning.

and subsequently cognitive dysfunction [29]. These studies demonstrate the complex interaction between TNF-a receptor signalling and the effects that downstream proteins, like NF-KB have on neurotrophins production. This relationship between TNF- $\alpha$ and neurotrophins demonstrates the direct or indirect role that TNF-a plays in hippocampal development and neurogenesis.

\section{TNF-a signalling in the progression and development of cognitive dysfuntions}

Neuropsychiatric conditions could originate from and often result in neural degeneration and increased inflammation in the CNS as well as in the periphery [99]. An exaggerated expression of TNF-a is found to be a common pathological feature in diseases with cognitive impairments such as depression, schizophrenia, and MS [7,100,101]. The following sections focus more elaborately on studies that demonstrate how this up-regulation of TNF-a acts on the progression and development of these conditions and the possible mechanisms through which TNF-a influences the cognitive deficits seen in the mentioned illnesses. Table 2 summarises some important studies providing evidence for the effect of increased or reduced/no expression of TNF-a within the CNS respectively.

\section{Cognitive dysfunction in depression: relation to TNF-a expression}

MDD or clinical depression is a neuropsychiatric condition characterised by anhedonia, depressive mood and cognitive dysfunction. Patients with MDD have shown increased levels of inflammatory markers and macrophage activation $[100,102]$ in the periphery as well as in the CNS $[5,6]$. It is suggested that chronic stress and its association with inflammation [103] is found to suppress adult neurogenesis [104] and is thought to be another precursor for the onset of depression [105].

Increase in peripheral blood cytokine levels induced by lipopolysaccharide (LPS) or Salmonella typhi vaccination in healthy individuals caused symptoms of depression as well as fatigue, psychomotor slowing [106], and mental confusion $[6,107]$. These findings are consistent with animal studies demonstrating that the up-regulation of cytokines is related to sickness-like behavioural symptoms of anhedonia and dysfunction in cognitive function $[6,108]$. Both preclinical and clinical studies have demonstrated that cytokines, particularly TNF- $a$ and IL- 6 are upregulated in $\operatorname{MDD}[6,102,109,110]$. Under normal conditions, TNF- $a$ is required for neurogenesis and the development of memory and learning, as shown by murine studies $[6,111]$. However, continual exposure to these cytokines results in decreased neurogenesis, apoptosis and cognitive dysfunction $[6,67,112]$.

A recent animal study showed that TNF-a administered by intracerebroventricular route produced depressive-like behaviour in mice [113]. In another animal study that tested the effects of stress and depression on cytokine expression, higher levels of TNF-a and IL-1 $\beta$ mRNA were found in the neocortex, hippocampus and in the spleen of stressed rats, while anti-inflammatory cytokine IL-10 and transforming growth factor (TGF) and neurotropins such as BDNF were reduced [114]. Once at extremely low concentrations, BDNF causes depolarization and modulates LTP of hippocampal neurons $[29,115]$.

TNF- $a$ can further influence astrocytes and microglia to release nitrogen and oxygen reactive species that cause oxidative stress to neurons and glial cells $[6,67,112,116]$. Such oxidative damage is particularly noticeable in 
Table 2. Studies illustrating the effects of over-expression and under/no expression of TNF-a in the CNS.

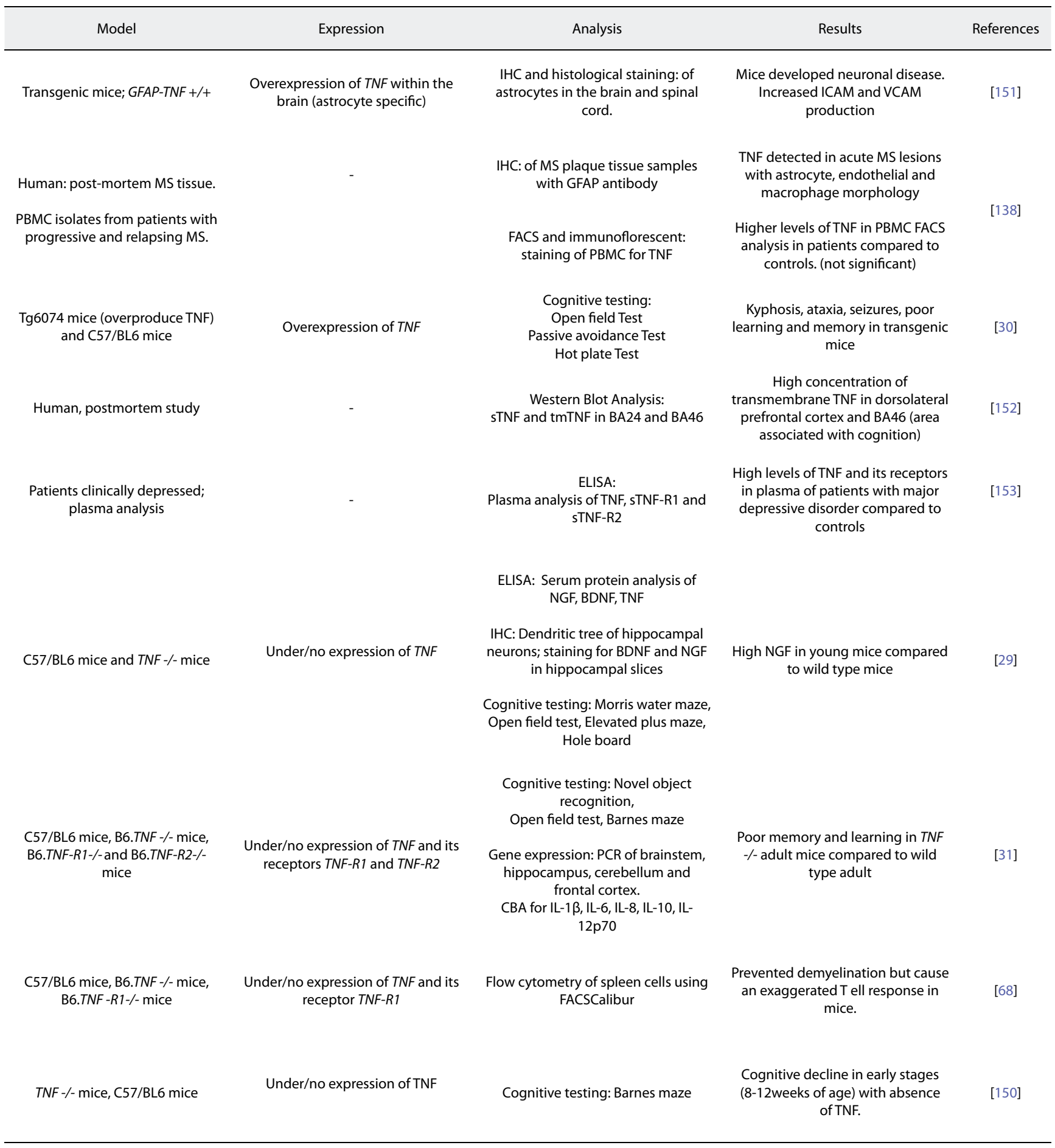

Legend: BDNF - brain-derived neurotrophic factor; NGF - nerve growth factor; ELISA - enzyme linked immunosorbent assay; IHC - immunohistochemistry; FACS - fluorescence activated cell sorting; MS - multiple sclerosis; PCR - polymerase chain reaction; EAE - experimental autoimmune encephalomyelitis; ICAM - intercellular adhesion molecule 1; VCAM vascular cell adhesion protein 1; PBMC - peripheral blood mononuclear cell; BA 46 - Brodmann area 46; BA 24 - Brodmann area 24. 
the prefrontal cortex (PFC) and the amygdala $[6,117,118]$, both of which are areas relevant to cognitive and emotional processing and are impaired in depression. Increased microglial activation was also observed in the PFC and hippocampus in post-mortem analysis of suicide patients compared to control subjects [119]; lending further evidence to the role of TNF-a in depression.

\section{Cognitive impairment in schizophrenia and its association with TNF-a}

Schizophrenia is regarded as a neurodegenerative disorder originally termed "dementia praecox" [2]. It is characterized by positive symptoms (hallucinations, delusions, and movement and thought disorders) and negative symptoms (anhedonia, listlessness) as well as cognitive dysfunction-like impairment in working memory, attention and social problem solving [20]. Cognitive impairments usually precede the onset of positive and negative symptoms [120].

Recent evidence points to increased inflammation occurring in the CNS as well as the periphery of schizophrenic patients suggesting a role of cytokines like IL-1, IL-6 and TNF- $a$ in schizophrenia $[101,121,122]$. Serum cytokine levels of patients with chronic schizophrenia compared to normal healthy controls showed significantly higher levels of TNF-a in patients [15] higher concentrations of soluble TNF- $a-R 1$ and TNF-a-R2 [123]. Studies have shown that G308A polymorphisms of TNF gene is possibly involved in the aetiology of schizophrenia [124-126]. Furthermore, TNF is located on the short arm of chromosome 6 (6p21.1-21.3), a locus that is modulating the predisposition to schizophrenia $[127,128]$.

A possible mechanism through which cytokines including TNF-a exert effects in schizophrenia is via neuregulin 1 [129]. Under normal conditions, the NEUREGULIN1 gene (NRG1) along with its receptor erbB4 are essential for myelination, plasticity as well as LTP formation by acting on post synaptic NMDAR and AMPAR [129,130], thereby underlining an important role in cognitive function. Studies of plasma cytokine levels in families having the NRG1, Val to Leu mutation, known to be associated with a higher risk for schizophrenia, showed that high levels of IL$1 \beta, \mathrm{IL}-6, \mathrm{IL}-10$ and TNF- $\alpha$ were associated with NGR1 mutation suggesting a relationship between NRG1 mutation and peripheral cytokine expression [131].

A BDNF associated pathway could be another avenue through which TNF-a may exert effects in schizophrenia. A postmortem analysis of hippocampal tissue revealed lower BDNF levels in schizophrenia patients compared to controls [132]. The reduced expression of BDNF in the hippocampus could be due to the effects of TNF- $a$ on hippocampal BDNF levels [29]. Since BDNF in turn is required for pyramidal cell morphogenesis in the $C A 1$ and $C A 3$ regions of the hippocampus [29], it can be suggested that increased TNF-a in schizophrenia has effects on the cognitive symptom spectrum of the disease. These findings are consistent with recent a metaanalysis showing reduced serum BDNF levels in chronic untreated schizophrenia patients [133].

\section{TNF-a associated cognitive dysfunction in MS}

MS is an autoimmune neurodegenerative disease characterized by demyelination and axonal loss of neurons in the CNS as well as oligodendrogliosis [134]. This demyelination affects the ability of neurons to communicate with each other resulting in a loss of sensory and motor function. The disease is associated with a large spectrum of symptoms that include muscle weakness, ataxia, dysarthria (caused by demyelination of neurons in the spinal cord), optic neuritis as well as significant cognitive impairment, especially memory impairments [3]. MS pathology is associated with inflammation that is characterized by increased expression of pro-inflammatory cytokines, particularly of TNF-a - both in the CNS as well as the periphery [7]. In humans, higher levels of TNF-a were observed in the cerebrospinal fluid (CSF) of patients with chronic progressive MS as opposed to patients with stable MS. Furthermore, these elevated cytokine levels correlated with the degree of disability [7]. In animal model of MS (EAE), TNF- $a$ is predominately produced by infiltrating $T$ cells and macrophages as well as resident microglial cells and a neutralization results in amelioration of the neurological symptoms such as paralysis [23,135-137]. This observation together with high numbers of TNF-a-positive astrocytes and microglia gave reason to assume that TNF-a is directly involved in the progression of MS $[138,139]$. Nevertheless, an essential role for TNF-a was also shown in down regulating and inactivating detrimental autoimmune $T$ cell response against myelin antigens and protecting from chronic EAE [140]. Interestingly, high levels of TNF-a caused inactivation of deleterious autospecific $T$ cell responses but resulted in progression of disease and excessive demyelination, whereas lower TNF-a levels prevented excessive demyelination but caused exaggerated $\mathrm{T}$ cell responses [68]. The availability of genedeficient mice $\left(T N F^{-1-}\right)$ allowed experiments that demonstrated that TNF- $\alpha$ is required during the initial stages of the disease. Myelin/oligodendrocyte glycoprotein (MOG)immunized mice showed delayed onset and a milder course of the disease compared to wildtype (WT) mice suggesting that the cytokine may be required for leukocyte activation during initial stages rather than having a specific role in the progression of the disease. This hypothesis was strengthened by findings that at the peak of $E A E$, inflammation in WT and $\mathrm{TNF}^{-1-}$ mice was comparable and both strains exhibited a perivascular and submeningeal infiltration of CD45+ cells as well as microglial activation [141]. Additionally, a dual role for TNF-a receptors was established in the EAE model. TNF-R2-/- mice showed increased demyelination compared to TNF-R1-/-, and TNF-a double knockout mice (TNF-R1/R2-/-) mice, along with increased infiltration of CD4+ and MHC II cells, supporting a neuroprotective role of $\mathrm{R} 2$ receptor [142].

In EAE learning and memory is impaired [143]. Postmortem hippocampal analysis of the mice in this study [143] revealed a decrease in the levels of choline acetyl transferase (ChAT) and NGF expression in the hippocampus, especially in the late phase of the disease. Animal studies using the Barnes maze (cognitive testing tool to measure spatial memory and 
learning in mice) could correlate impairment in cognition with morphological changes in these mice such as low CA1 volume and high apoptosis of CA1 hippocampal neurons measured by increased levels of TUNELpositive cells (apoptotic cells) as well as high microglial activation [22]. The cognitive deficits observed in these mice, which were potentially caused by the effects of the autoinflammation on the hippocampus, were linked to the effects of TNF-a-dependent deregulation on neurotrophic expression as well as on LTP and LTD formation. Neuroimaging studies have supported these findings and have revealed that MS lesions are associated with a decrease in volume of hippocampus as well as cingulate gyrus and PFC [144]. The effects of TNF- $a$ are not merely restricted to cognitive dysfunction seen in the above pathologies. Patients with schizophrenia as well as patients affected by chronic inflammatory diseases such as MS and RA also exhibit symptoms of depression, further emphasizing the role of inflammation in depression [145]. TNF-a has been linked to the aetiology of depressive behaviours in the above mentioned conditions; additionally the effects of TNF- $a$ in MDD are evident.

\section{DISCUSSION}

Though the major factors that play a role in TNF-a signalling have been identified, the exact mechanisms of their actions are yet to be determined. Further work needs to be done to elucidate the exact mechanisms and signalling pathways that involve TNF-adependent production of neurotrophins.

Due to the upregulated pro-inflammatory environment developed in the above mentioned conditions, the use of nonsteroidal anti-inflammatory drugs is gaining some momentum as a treatment modality. A range of biological antagonists is available such as Infliximab, a chimeric bivalent lgG1 monoclonal antibody composed of a human constant region and murine variable regions, Adalimumab - a humanized bivalent mouse IgG1 monoclonal antibody, and Etanercept - a fusion protein comprised of human IgG fused to a dimer of the extracellular regions of TNF-a-R2. Additionally anti-TNF therapy is being considered as an option in improving postoperative cognitive dysfunction [146].

However, there are two problems with these techniques. First, the BBB prevents a deep penetration into the CNS tissue. Second, while basal levels of TNF- $a$ are still required for normal functioning, animal models have shown that the complete lack of TNF-a due to genetic modification results in cognitive impairment [31]. This is possibly due to the influence that TNF-a exerts on NGF and BDNF. An imbalance in TNF- $a$ causes subsequent deregulation in these neurotrophins ultimately leading to morphological changes in the hippocampus such as decreased arborisation of pyramidal neurons [29].

Additionally, the role TNF-a plays in LTP and LTD formation by up-regulation of AMPA receptors [84] and endocytosis of GABA receptors [32] is crucial in the development of synaptic neuroplasticity related memory and learning [147]. Therefore, though complete blockage may prove to be initially beneficial, long-term negative effects may manifest and make further research into these effects necessary.

The complex signalling pathways of TNF- $a$ and its receptors and the duality of its function in being both neuroprotective and neurodegenerative make for a compelling argument against the validity and long term benefits of anti-TNF- $a$ therapies. TNF- $a$ may both exacerbate and attenuate cognitive dysfunction depending on the physiological context [148,149]. Clearer perspectives into TNF-a signalling and pharmacological interventions that can target specific apoptotic factors in the TNF-a receptorassociated pathways (Figure 3), rather than complete blockage of TNF-a or of its receptors would make for more effective therapeutics in treatment of neurological disorders in which TNF- $a$ is an active participant.

References

[1] Collins P.Y., Patel V., Joestl S.S., March D., Insel T.R., Daar A.S., et al., Grand challenges in global mental health, Nature, 2011, 475, 27-30

[2] Lieberman J.A., Is schizophrenia a neurodegenerative disorder? A clinical and neurobiological perspective, Biol. Psychiatry, 1999, 46, 729-739

[3] Mandolesi G., Grasselli G., Musumeci G.,Centonze D., Cognitive deficits in experimental autoimmune encephalomyelitis: neuroinflammation and synaptic degeneration, Neurol. Sci., 2010, 31, S255-259

[4] Kupfer D.J., Frank E.,Phillips M.L., Major depressive disorder: new clinical, neurobiological, and treatment perspectives, Lancet, 2012, 379, 1045-1055

[5] Zorrilla E.P., Luborsky L., McKay J.R., Rosenthal R., Houldin A., Tax A., et al., The relationship of depression and stressors to immunological assays: a meta-analytic review, Brain. Behav. Immun., 2001, 15, 199-226
[6] Miller A.H., Maletic V.,Raison C.L., Inflammation and its discontents: the role of cytokines in the pathophysiology of major depression, Biol. Psychiatry, 2009, 65, 732-741

[7] Sharief M.K.,Hentges R., Association between tumor necrosis factoralpha and disease progression in patients with multiple sclerosis, $\mathrm{N}$. Engl. J. Med., 1991, 325, 467-472

[8] Blume J., Douglas S.D.,Evans D.L., Immune suppression and immune activation in depression, Brain Behav. Immun., 2011, 25, 221-229

[9] Zunszain P.A., Hepgul N.,Pariante C.M., Inflammation and Depression, Curr. Top. Behav. Neurosci., 2012, [Epub ahead of print]

[10] Lieberman A.P., Pitha P.M., Shin H.S.,Shin M.L., Production of tumor necrosis factor and other cytokines by astrocytes stimulated with lipopolysaccharide or a neurotropic virus, Proc. Natl. Acad. Sci. USA, $1989,86,6348-6352$ 
[11] Rock R.B., Gekker G., Hu S., Sheng W.S., Cheeran M., Lokensgard J.R., et al., Role of microglia in central nervous system infections, Clin. Microbiol. Rev., 2004, 17, 942-964

[12] Tsakiri N., Kimber I., Rothwell N.J.,Pinteaux E., Differential effects of interleukin-1 alpha and beta on interleukin- 6 and chemokine synthesis in neurones, Mol. Cell. Neurosci., 2008, 38, 259-265

[13] Kaiya H., Uematsu M., Ofuji M., Nishida A., Takeuchi K., Nozaki M., et al., Elevated plasma prostaglandin E2 levels in schizophrenia, J. Neural. Transm., 1989, 77, 39-46

[14] Dickerson F., Stallings C., Origoni A., Boronow J.,Yolken R., C-reactive protein is associated with the severity of cognitive impairment but not of psychiatric symptoms in individuals with schizophrenia, Schizophr. Res., 2007, 93, 261-265

[15] Theodoropoulou S., Spanakos G., Baxevanis C.N., Economou M., Gritzapis A.D., Papamichail M.P., et al., Cytokine serum levels, autologous mixed lymphocyte reaction and surface marker analysis in never medicated and chronically medicated schizophrenic patients, Schizophr. Res., 2001, 47, 13-25

[16] Radewicz K., Garey L.J., Gentleman S.M.,Reynolds R., Increase in HLA-DR immunoreactive microglia in frontal and temporal cortex of chronic schizophrenics, J. Neuropathol. Exp. Neurol., 2000, 59, 137150

[17] Bayer T.A., Buslei R., Havas L.,Falkai P., Evidence for activation of microglia in patients with psychiatric illnesses, Neurosci. Lett., 1999, 271, 126-128

[18] van Berckel B.N., Bossong M.G., Boellaard R., Kloet R., Schuitemaker A., Caspers E., et al., Microglia activation in recent-onset schizophrenia: a quantitative (R)-[11C]PK11195 positron emission tomography study, Biol. Psychiatry, 2008, 64, 820-822

[19] Doorduin J., de Vries E.F., Willemsen A.T., de Groot J.C., Dierckx R.A.,Klein H.C., Neuroinflammation in schizophrenia-related psychosis: a PET study, J. Nucl. Med., 2009, 50, 1801-1807

[20] Niitsu T., Shirayama Y., Matsuzawa D., Hasegawa T., Kanahara N., Hashimoto T., et al., Associations of serum brain-derived neurotrophic factor with cognitive impairments and negative symptoms in schizophrenia, Prog. Neuropsychopharmacol. Biol. Psychiatry, 2011, 35, 1836-1840

[21] Campbell S., Marriott M., Nahmias C.,MacQueen G.M., Lower hippocampal volume in patients suffering from depression: a metaanalysis, Am. J. Psychiatry, 2004, 161, 598-607

[22] Ziehn M.O., Avedisian A.A., Tiwari-Woodruff S.,Voskuhl R.R., Hippocampal CA1 atrophy and synaptic loss during experimental autoimmune encephalomyelitis, EAE, Lab. Invest., 2010, 90, 774-786

[23] Renno T., Krakowski M., Piccirillo C., Lin J.Y.,Owens T., TNF-alpha expression by resident microglia and infiltrating leukocytes in the central nervous system of mice with experimental allergic encephalomyelitis. Regulation by Th1 cytokines, J. Immunol., 1995, 154, 944-953

[24] Appenzeller S., Bertolo M.B.,Costallat L.T., Cognitive impairment in rheumatoid arthritis, Methods Find. Exp. Clin. Pharmacol., 2004, 26, 339-343
[25] El-Tantawy A.M., El-Sayed A.E., Kora B.A.,Amin R.T., Psychiatric morbidity associated with some cytokines (IL-1beta, IL-12, IL-18 and TNF-alpha) among rheumatoid arthritis patients, Egypt. J. Immunol., 2008, 15, 1-11

[26] Hider S.L., Tanveer W., Brownfield A., Mattey D.L.,Packham J.C., Depression in RA patients treated with anti-TNF is common and under-recognized in the rheumatology clinic, Rheumatology (Oxford), 2009, 48, 1152-1154

[27] Aloe L., Tuveri M.A.,Levi-Montalcini R., Nerve growth factor and distribution of mast cells in the synovium of adult rats, Clin. Exp. Rheumatol., 1992, 10, 203-204

[28] Stellwagen D.,Malenka R.C., Synaptic scaling mediated by glial TNFalpha, Nature, 2006, 440, 1054-1059

[29] Golan H., Levav T., Mendelsohn A.,Huleihel M., Involvement of tumor necrosis factor alpha in hippocampal development and function, Cereb. Cortex, 2004, 14, 97-105

[30] Fiore M., Probert L., Kollias G., Akassoglou K., Alleva E.,Aloe L., Neurobehavioral alterations in developing transgenic mice expressing TNF-alpha in the brain, Brain Behav. Immun., 1996, 10, 126-138

[31] Baune B.T., Wiede F., Braun A., Golledge J., Arolt V.,Koerner H., Cognitive dysfunction in mice deficient for TNF- and its receptors, Am. J. Med. Genet. B Neuropsychiatr. Genet., 2008, 147B, 1056-1064

[32] Stellwagen D., Beattie E.C., Seo J.Y.,Malenka R.C., Differential regulation of AMPA receptor and GABA receptor trafficking by tumor necrosis factor-alpha, J. Neurosci., 2005, 25, 3219-3228

[33] Moher D., Liberati A., Tetzlaff J.,Altman D.G., Preferred reporting items for systematic reviews and meta-analyses: the PRISMA statement, J. Clin. Epidemiol., 2009, 62, 1006-1012

[34] Medawar P.B., Immunity to homologous grafted skin; the fate of skin homografts transplanted to the brain, to subcutaneous tissue, and to the anterior chamber of the eye, Br. J. Exp. Pathol., 1948, 29, 58-69

[35] Barker C.F.,Billingham R.E., Immunologically privileged sites, Adv. Immunol., 1977, 25, 1-54

[36] Ransohoff R.M., Kivisakk P.,Kidd G., Three or more routes for leukocyte migration into the central nervous system, Nat. Rev. Immunol., 2003, 3, 569-581

[37] Streilein J.W., Immune privilege as the result of local tissue barriers and immunosuppressive microenvironments, Curr. Opin. Immunol., 1993, 5, 428-432

[38] Tabakman R., Lecht S., Sephanova S., Arien-Zakay H.,Lazarovici P., Interactions between the cells of the immune and nervous system: neurotrophins as neuroprotection mediators in CNS injury, Prog. Brain Res., 2004, 146, 387-401

[39] Garay P.A.,McAllister A.K., Novel roles for immune molecules in neural development: implications for neurodevelopmental disorders, Front. Synaptic Neurosci., 2010, 2, 136

[40] Boulanger L.M.,Shatz C.J., Immune signalling in neural development, synaptic plasticity and disease, Nat. Rev. Neurosci., 2004, 5, 521-531

[41]Zlokovic B.V., The blood-brain barrier in health and chronic neurodegenerative disorders, Neuron, 2008, 57, 178-201 
[42] Banks W.A.,Erickson M.A., The blood-brain barrier and immune function and dysfunction, Neurobiol. Dis., 2010, 37, 26-32

[43] Engelhardt B., Regulation of immune cell entry into the central nervous system, Results Probl. Cell. Differ., 2006, 43, 259-280

[44] Brietzke E., Stertz L., Fernandes B.S., Kauer-Sant'anna M., Mascarenhas M., Escosteguy Vargas A., et al., Comparison of cytokine levels in depressed, manic and euthymic patients with bipolar disorder, J. Affect. Disord., 2009, 116, 214-217

[45] Maccioni R.B., Rojo L.E., Fernandez J.A.,Kuljis R.O., The role of neuroimmunomodulation in Alzheimer's disease, Ann. NY Acad. Sci., 2009, 1153, 240-246

[46] Bossu P., Ciaramella A., Salani F., Bizzoni F., Varsi E., Di lulio F., et al., Interleukin-18 produced by peripheral blood cells is increased in Alzheimer's disease and correlates with cognitive impairment, Brain Behav. Immun., 2008, 22, 487-492

[47] Cross A.H.,Waubant E., MS and the B cell controversy, Biochim. Biophys. Acta, 2011, 1812, 231-238

[48] Pan W.,Kastin A.J., TNFalpha transport across the blood-brain barrier is abolished in receptor knockout mice, Exp. Neurol., 2002, 174, 193200

[49] Miric D., Katanic R., Kisic B., Zoric L., Miric B., Mitic R., et al., Oxidative stress and myeloperoxidase activity during bacterial meningitis: effects of febrile episodes and the BBB permeability, Clin. Biochem., 2010, 43, 246-252

[50] Leib S.L.,Tauber M.G., Pathogenesis of bacterial meningitis, Infect. Dis. Clin. North Am., 1999, 13, 527-548, v-vi

[51] Nishioku T., Matsumoto J., Dohgu S., Sumi N., Miyao K., Takata F., et al., Tumor necrosis factor-alpha mediates the blood-brain barrier dysfunction induced by activated microglia in mouse brain microvascular endothelial cells, J. Pharmacol. Sci., 2010, 112, 251-254

[52] Forster C., Burek M., Romero I.A., Weksler B., Couraud P.O.,Drenckhahn D., Differential effects of hydrocortisone and TNFalpha on tight junction proteins in an in vitro model of the human blood-brain barrier, J. Physiol., 2008, 586, 1937-1949

[53] Aslam M., Ahmad N., Srivastava R.,Hemmer B., TNF-alpha induced NFkappaB signaling and p65 (RelA) overexpression repress Cldn5 promoter in mouse brain endothelial cells, Cytokine, 2012, 57, 269275

[54] Wake H., Moorhouse A.J.,Nabekura J., Functions of microglia in the central nervous system - beyond the immune response, Neuron Glia Biol., 2012, 1-7

[55] Butovsky O., Talpalar A.E., Ben-Yaakov K.,Schwartz M., Activation of microglia by aggregated beta-amyloid or lipopolysaccharide impairs MHC-II expression and renders them cytotoxic whereas IFN-gamma and IL-4 render them protective, Mol. Cell. Neurosci., 2005, 29, 381-393

[56] Morgan S.C., Taylor D.L.,Pocock J.M., Microglia release activators of neuronal proliferation mediated by activation of mitogen-activated protein kinase, phosphatidylinositol-3-kinase/Akt and delta-Notch signalling cascades, J. Neurochem., 2004, 90, 89-101

[57] Medana I.M., Hunt N.H.,Chaudhri G., Tumor necrosis factor-alpha expression in the brain during fatal murine cerebral malaria: evidence for production by microglia and astrocytes, Am. J. Pathol., 1997, 150, 1473-1486

[58] Tracey K.J., Tumor necrosis factor (cachectin) in the biology of septic shock syndrome, Circ. Shock, 1991, 35, 123-128

[59] Bielefeldt Ohmann H., Campos M., Snider M., Rapin N., Beskorwayne T., Popowych Y., et al., Effect of chronic administration of recombinant bovine tumor necrosis factor to cattle, Vet. Pathol., 1989, 26, 462-472

[60] Probert L., Keffer J., Corbella P., Cazlaris H., Patsavoudi E., Stephens S., et al., Wasting, ischemia, and lymphoid abnormalities in mice expressing $\mathrm{T}$ cell-targeted human tumor necrosis factor transgenes, J. Immunol., 1993, 151, 1894-1906

[61] Das S.,Basu A., Inflammation: a new candidate in modulating adult neurogenesis, J. Neurosci. Res., 2008, 86, 1199-1208

[62] Albensi B.C.,Mattson M.P., Evidence for the involvement of TNF and NF-kappaB in hippocampal synaptic plasticity, Synapse, 2000, 35, 151-159

[63] Horiuchi T., Mitoma H., Harashima S., Tsukamoto H.,Shimoda T., Transmembrane TNF-alpha: structure, function and interaction with anti-TNF agents, Rheumatology (Oxford), 2010, 49, 1215-1228

[64] Wajant H., Pfizenmaier K.,Scheurich P., Tumor necrosis factor signaling, Cell. Death Differ., 2003, 10, 45-65

[65] Black R.A., Rauch C.T., Kozlosky C.J., Peschon J.J., Slack J.L., Wolfson M.F., et al., A metalloproteinase disintegrin that releases tumournecrosis factor-alpha from cells, Nature, 1997, 385, 729-733

[66] McCoy M.K.,Tansey M.G., TNF signaling inhibition in the CNS: implications for normal brain function and neurodegenerative disease, J. Neuroinflammation, 2008, 5, 45

[67] Li J., Ramenaden E.R., Peng J., Koito H., Volpe J.J.,Rosenberg P.A., Tumor necrosis factor alpha mediates lipopolysaccharide-induced microglial toxicity to developing oligodendrocytes when astrocytes are present, J. Neurosci., 2008, 28, 5321-5330

[68] Kassiotis G.,Kollias G., Uncoupling the proinflammatory from the immunosuppressive properties of tumor necrosis factor (TNF) at the p55 TNF receptor level: implications for pathogenesis and therapy of autoimmune demyelination, J. Exp. Med., 2001, 193, 427-434

[69] Grell M., Wajant H., Zimmermann G.,Scheurich P., The type 1 receptor (CD120a) is the high-affinity receptor for soluble tumor necrosis factor, Proc. Natl. Acad. Sci. USA, 1998, 95, 570-575

[70] Chen G.,Goeddel D.V., TNF-R1 signaling: a beautiful pathway, Science, 2002, 296, 1634-1635

[71] Hsu H., Xiong J.,Goeddel D.V., The TNF receptor 1-associated protein TRADD signals cell death and NF-kappa B activation, Cell, 1995, 81, 495-504

[72] Hsu H., Shu H.B., Pan M.G.,Goeddel D.V., TRADD-TRAF2 and TRADDFADD interactions define two distinct TNF receptor 1 signal transduction pathways, Cell, 1996, 84, 299-308

[73] Micheau O.,Tschopp J., Induction of TNF receptor I-mediated apoptosis via two sequential signaling complexes, Cell, 2003, 114, 181-190

[74] Shu H.B., Takeuchi M.,Goeddel D.V., The tumor necrosis factor receptor 2 signal transducers TRAF2 and c-IAP1 are components of 
the tumor necrosis factor receptor 1 signaling complex, Proc. Natl. Acad. Sci USA, 1996, 93, 13973-13978

[75] Winston B.W., Lange-Carter C.A., Gardner A.M., Johnson G.L.,Riches D.W., Tumor necrosis factor alpha rapidly activates the mitogenactivated protein kinase (MAPK) cascade in a MAPK kinase kinasedependent, c-Raf-1-independent fashion in mouse macrophages, Proc. Natl. Acad. Sci. USA, 1995, 92, 1614-1618

[76] Tobiume K., Matsuzawa A., Takahashi T., Nishitoh H., Morita K., Takeda $\mathrm{K}$., et al., ASK1 is required for sustained activations of JNK/p38 MAP kinases and apoptosis, EMBO Rep., 2001, 2, 222-228

[77] Ghosh S.,Karin M., Missing pieces in the NF-kappaB puzzle, Cell, 2002, 109 Suppl, S81-96

[78] Camandola S.,Mattson M.P., NF-kappa B as a therapeutic target in neurodegenerative diseases, Expert Opin. Ther. Targets, 2007, 11, 123-132

[79] Rothe M., Pan M.G., Henzel W.J., Ayres T.M.,Goeddel D.V., The TNFR2TRAF signaling complex contains two novel proteins related to baculoviral inhibitor of apoptosis proteins, Cell, 1995, 83, 1243-1252

[80] Marchetti L., Klein M., Schlett K., Pfizenmaier K.,Eisel U.L., Tumor necrosis factor (TNF)-mediated neuroprotection against glutamateinduced excitotoxicity is enhanced by $\mathrm{N}$-methyl-D-aspartate receptor activation. Essential role of a TNF receptor 2-mediated phosphatidylinositol 3-kinase-dependent NF-kappa B pathway, J. Biol. Chem., 2004, 279, 32869-32881

[81] Bliss T.V.,Collingridge G.L., A synaptic model of memory: long-term potentiation in the hippocampus, Nature, 1993, 361, 31-39

[82] Wang G., Gilbert J.,Man H.Y., AMPA receptor trafficking in homeostatic synaptic plasticity: functional molecules and signaling cascades, Neural Plast., 2012, 2012, 825364

[83] Lipsky R.H., Xu K., Zhu D., Kelly C., Terhakopian A., Novelli A., et al., Nuclear factor kappaB is a critical determinant in N-methyl-Daspartate receptor-mediated neuroprotection, J. Neurochem., 2001, $78,254-264$

[84] Beattie E.C., Stellwagen D., Morishita W., Bresnahan J.C., Ha B.K., Von Zastrow M., et al., Control of synaptic strength by glial TNFalpha, Science, 2002, 295, 2282-2285

[85] Butler M.P., O'Connor J.J.,Moynagh P.N., Dissection of tumor-necrosis factor-alpha inhibition of long-term potentiation (LTP) reveals a p38 mitogen-activated protein kinase-dependent mechanism which maps to early-but not late-phase LTP, Neuroscience, 2004, 124, 319-326

[86] Bolshakov V.Y., Carboni L., Cobb M.H., Siegelbaum S.A.,Belardetti F., Dual MAP kinase pathways mediate opposing forms of long-term plasticity at CA3-CA1 synapses, Nat. Neurosci., 2000, 3, 1107-1112

[87] Wang Q., Walsh D.M., Rowan M.J., Selkoe D.J.,Anwyl R., Block of long-term potentiation by naturally secreted and synthetic amyloid beta-peptide in hippocampal slices is mediated via activation of the kinases c-Jun N-terminal kinase, cyclin-dependent kinase 5, and p38 mitogen-activated protein kinase as well as metabotropic glutamate receptor type 5, J. Neurosci., 2004, 24, 3370-3378

[88] Ono K.,Han J., The p38 signal transduction pathway: activation and function, Cell. Signal., 2000, 12, 1-13
[89] Pickering M., Cumiskey D.,O'Connor J.J., Actions of TNF-alpha on glutamatergic synaptic transmission in the central nervous system, Exp. Physiol., 2005, 90, 663-670

[90] Hallbook F., Evolution of the vertebrate neurotrophin and Trk receptor gene families, Curr. Opin. Neurobiol., 1999, 9, 616-621

[91] Huang E.J.,Reichardt L.F., Neurotrophins: roles in neuronal development and function, Annu. Rev. Neurosci., 2001, 24, 677-736

[92] Lewin G.R.,Barde Y.A., Physiology of the neurotrophins, Annu. Rev. Neurosci., 1996, 19, 289-317

[93] Sofroniew M.V., Howe C.L.,Mobley W.C., Nerve growth factor signaling, neuroprotection, and neural repair, Annu. Rev. Neurosci., 2001, 24, 1217-1281

[94] Henderson C.E., Role of neurotrophic factors in neuronal development, Curr. Opin. Neurobiol., 1996, 6, 64-70

[95] Aloe L., Properzi F., Probert L., Akassoglou K., Kassiotis G., Micera A., et al., Learning abilities, NGF and BDNF brain levels in two lines of TNFalpha transgenic mice, one characterized by neurological disorders, the other phenotypically normal, Brain Res., 1999, 840, 125-137

[96] Takei Y.,Laskey R., Interpreting crosstalk between TNF-alpha and NGF: potential implications for disease, Trends Mol. Med., 2008, 14, 381388

[97] Takei Y.,Laskey R., Intracellular and intercellular cross talk between NGF and TNF, Adv. Exp. Med. Biol., 2011, 691, 559-565

[98] Saha R.N., Liu X.,Pahan K., Up-regulation of BDNF in astrocytes by TNF-alpha: a case for the neuroprotective role of cytokine, J. Neuroimmune Pharmacol., 2006, 1, 212-222

[99] Streit W.J., Mrak R.E.,Griffin W.S., Microglia and neuroinflammation: a pathological perspective, J. Neuroinflammation, 2004, 1, 14

[100] Khairova R.A., Machado-Vieira R., Du J.,Manji H.K., A potential role for pro-inflammatory cytokines in regulating synaptic plasticity in major depressive disorder, Int. J. Neuropsychopharmacol., 2009, 12, 561-578

[101] Potvin S., Stip E., Sepehry A.A., Gendron A., Bah R.,Kouassi E., Inflammatory cytokine alterations in schizophrenia: a systematic quantitative review, Biol. Psychiatry, 2008, 63, 801-808

[102] Schmidt H.D., Shelton R.C.,Duman R.S., Functional biomarkers of depression: diagnosis, treatment, and pathophysiology, Neuropsychopharmacology, 2011, 36, 2375-2394

[103] Eyre H.,Baune B.T., Neuroimmunological effects of physical exercise in depression, Brain Behav. Immun., 2012, 26, 251-266

[104] Mirescu C.,Gould E., Stress and adult neurogenesis, Hippocampus, $2006,16,233-238$

[105] Leonard B.E.,Myint A., The psychoneuroimmunology of depression, Hum. Psychopharmacol., 2009, 24, 165-175

[106] Brydon L., Harrison N.A., Walker C., Steptoe A.,Critchley H.D., Peripheral inflammation is associated with altered substantia nigra activity and psychomotor slowing in humans, Biol. Psychiatry, 2008, 63, 1022-1029

[107] Reichenberg A., Yirmiya R., Schuld A., Kraus T., Haack M., Morag A., et al., Cytokine-associated emotional and cognitive disturbances in humans, Arch. Gen. Psychiatry, 2001, 58, 445-452 
[108] Dantzer R., O'Connor J.C., Freund G.G., Johnson R.W.,Kelley K.W., From inflammation to sickness and depression: when the immune system subjugates the brain, Nat. Rev. Neurosci., 2008, 9, 46-56

[109] Dowlati Y., Herrmann N., Swardfager W., Liu H., Sham L., Reim E.K., et al., A meta-analysis of cytokines in major depression, Biol. Psychiatry, 2010, 67, 446-457

[110] Howren M.B., Lamkin D.M.,Suls J., Associations of depression with C-reactive protein, IL-1, and IL-6: a meta-analysis, Psychosom. Med., 2009, 71, 171-186

[111] Bernardino L., Agasse F., Silva B., Ferreira R., Grade S.,Malva J.O., Tumor necrosis factor-alpha modulates survival, proliferation, and neuronal differentiation in neonatal subventricular zone cell cultures, Stem Cells, 2008, 26, 2361-2371

[112] Tilleux S.,Hermans E., Neuroinflammation and regulation of glial glutamate uptake in neurological disorders, J. Neurosci. Res., 2007, 85, 2059-2070

[113] Kaster M.P., Gadotti V.M., Calixto J.B., Santos A.R.,Rodrigues A.L., Depressive-like behavior induced by tumor necrosis factor-alpha in mice, Neuropharmacology, 2012, 62, 419-426

[114] You Z., Luo C., Zhang W., Chen Y., He J., Zhao Q., et al., Pro- and antiinflammatory cytokines expression in rat's brain and spleen exposed to chronic mild stress: Involvement in depression, Behav. Brain Res., 225, 135-141

[115] Kafitz K.W., Rose C.R.,Konnerth A., Neurotrophin-evoked rapid excitation of central neurons, Prog. Brain Res., 2000, 128, 243-249

[116] Gavillet M., Allaman I.,Magistretti P.J., Modulation of astrocytic metabolic phenotype by proinflammatory cytokines, Glia, 2008, 56, 975-989

[117] Hamidi M., Drevets W.C.,Price J.L., Glial reduction in amygdala in major depressive disorder is due to oligodendrocytes, Biol. Psychiatry, 2004, 55, 563-569

[118] Ongur D., Drevets W.C.,Price J.L., Glial reduction in the subgenual prefrontal cortex in mood disorders, Proc. Natl. Acad. Sci. USA, 1998, 95, 13290-13295

[119] Steiner J., Bielau H., Brisch R., Danos P., Ullrich O., Mawrin C., et al., Immunological aspects in the neurobiology of suicide: elevated microglial density in schizophrenia and depression is associated with suicide, J. Psychiatr. Res., 2008, 42, 151-157

[120] Arguello P.A.,Gogos J.A., Cognition in mouse models of schizophrenia susceptibility genes, Schizophr. Bull., 2010, 36, 289300

[121] Drzyzga L., Obuchowicz E., Marcinowska A.,Herman Z.S., Cytokines in schizophrenia and the effects of antipsychotic drugs, Brain Behav. Immun., 2006, 20, 532-545

[122] Muller N., Riedel M., Gruber R., Ackenheil M.,Schwarz M.J., The immune system and schizophrenia. An integrative view, Ann. NY Acad. Sci., 2000, 917, 456-467

[123] Coelho F.M., Reis H.J., Nicolato R., Romano-Silva M.A., Teixeira M.M., Bauer M.E., et al., Increased serum levels of inflammatory markers in chronic institutionalized patients with schizophrenia, Neuroimmunomodulation, 2008, 15, 140-144
[124] Boin F., Zanardini R., Pioli R., Altamura C.A., Maes M.,Gennarelli M., Association between -G308A tumor necrosis factor alpha gene polymorphism and schizophrenia, Mol. Psychiatry, 2001, 6, 79-82

[125] Schwab S.G., Mondabon S., Knapp M., Albus M., Hallmayer J., Borrmann-Hassenbach M., et al., Association of tumor necrosis factor alpha gene - G308A polymorphism with schizophrenia, Schizophr. Res., 2003, 65, 19-25

[126] Wilson A.G., Symons J.A., McDowell T.L., McDevitt H.O.,Duff G.W., Effects of a polymorphism in the human tumor necrosis factor alpha promoter on transcriptional activation, Proc. Natl. Acad. Sci. USA, 1997, 94, 3195-3199

[127] Shi J., Levinson D.F., Duan J., Sanders A.R., Zheng Y., Pe'er I., et al., Common variants on chromosome $6 \mathrm{p} 22.1$ are associated with schizophrenia, Nature, 2009, 460, 753-757

[128] Ingason A., Rujescu D., Cichon S., Sigurdsson E., Sigmundsson T., Pietilainen O.P., et al., Copy number variations of chromosome 16p13.1 region associated with schizophrenia, Mol. Psychiatry, 2011, 16, 17-25

[129] Stefansson H., Sigurdsson E., Steinthorsdottir V., Bjornsdottir S., Sigmundsson T., Ghosh S., et al., Neuregulin 1 and susceptibility to schizophrenia, Am. J. Hum. Genet., 2002, 71, 877-892

[130] Li B., Woo R.S., Mei L.,Malinow R., The neuregulin-1 receptor erbB4 controls glutamatergic synapse maturation and plasticity, Neuron, 2007, 54, 583-597

[131] Marballi K., Quinones M.P., Jimenez F., Escamilla M.A., Raventos H., Soto-Bernardini M.C., et al., In vivo and in vitro genetic evidence of involvement of neuregulin 1 in immune system dysregulation, J. Mol. Med. (Berl), 2010, 88, 1133-1141

[132] Durany N., Michel T., Zochling R., Boissl K.W., Cruz-Sanchez F.F., Riederer $\mathrm{P}_{\text {., }}$ et al., Brain-derived neurotrophic factor and neurotrophin 3 in schizophrenic psychoses, Schizophr. Res., 2001, 52, 79-86

[133] Green M.J., Matheson S.L., Shepherd A., Weickert C.S.,Carr V.J., Brainderived neurotrophic factor levels in schizophrenia: a systematic review with meta-analysis, Mol. Psychiatry, 2011, 16, 960-972

[134] Lassmann H., Bruck W.,Lucchinetti C., Heterogeneity of multiple sclerosis pathogenesis: implications for diagnosis and therapy, Trends Mol. Med., 2001, 7, 115-121

[135] Korner H.,Sedgwick J.D., Tumour necrosis factor and lymphotoxin: molecular aspects and role in tissue-specific autoimmunity, Immunol. Cell Biol., 1996, 74, 465-472

[136] Ruddle N.H., Bergman C.M., McGrath K.M., Lingenheld E.G., Grunnet M.L., Padula S.J., et al., An antibody to lymphotoxin and tumor necrosis factor prevents transfer of experimental allergic encephalomyelitis, J. Exp. Med., 1990, 172, 1193-1200

[137] Korner H., Lemckert F.A., Chaudhri G., Etteldorf S.,Sedgwick J.D., Tumor necrosis factor blockade in actively induced experimental autoimmune encephalomyelitis prevents clinical disease despite activated T cell infiltration to the central nervous system, Eur. J. Immunol., 1997, 27, 1973-1981

[138] Selmaj K., Raine C.S., Cannella B.,Brosnan C.F., Identification of lymphotoxin and tumor necrosis factor in multiple sclerosis lesions, J. Clin. Invest., 1991, 87, 949-954 
[139] Kuroda Y.,Shimamoto Y., Human tumor necrosis factor-alpha augments experimental allergic encephalomyelitis in rats, J. Neuroimmunol., 1991, 34, 159-164

[140] Barten D.M.,Ruddle N.H., Vascular cell adhesion molecule-1 modulation by tumor necrosis factor in experimental allergic encephalomyelitis, J. Neuroimmunol., 1994, 51, 123-133

[141] Korner H., Riminton D.S., Strickland D.H., Lemckert F.A., Pollard J.D.,Sedgwick J.D., Critical points of tumor necrosis factor action in central nervous system autoimmune inflammation defined by gene targeting, J. Exp. Med., 1997, 186, 1585-1590

[142] Suvannavejh G.C., Lee H.O., Padilla J., Dal Canto M.C., Barrett T.A.,Miller S.D., Divergent roles for p55 and p75 tumor necrosis factor receptors in the pathogenesis of $\mathrm{MOG}(35-55)$-induced experimental autoimmune encephalomyelitis, Cell. Immunol., 2000, 205, 24-33

[143] D'Intino G., Paradisi M., Fernandez M., Giuliani A., Aloe L., Giardino L., et al., Cognitive deficit associated with cholinergic and nerve growth factor down-regulation in experimental allergic encephalomyelitis in rats, Proc. Natl. Acad. Sci. USA, 2005, 102, 3070-3075

[144] Roosendaal S.D., Hulst H.E., Vrenken H., Feenstra H.E., Castelijns J.A., Pouwels P.J., et al., Structural and functional hippocampal changes in multiple sclerosis patients with intact memory function, Radiology, 2010, 255, 595-604

[145] Anisman H., Merali Z.,Hayley S., Neurotransmitter, peptide and cytokine processes in relation to depressive disorder: comorbidity between depression and neurodegenerative disorders, Prog. Neurobiol., 2008, 85, 1-74

[146] Terrando N., Monaco C., Ma D., Foxwell B.M., Feldmann M.,Maze M., Tumor necrosis factor-alpha triggers a cytokine cascade yielding postoperative cognitive decline, Proc. Natl. Acad. Sci. USA, 2010, 107, 20518-20522

[147] McAfoose J.,Baune B.T., Evidence for a cytokine model of cognitive function, Neurosci. Biobehav. Rev., 2009, 33, 355-366

[148] Peschon J.J., Torrance D.S., Stocking K.L., Glaccum M.B., Otten C., Willis C.R., et al., TNF receptor-deficient mice reveal divergent roles for p55 and p75 in several models of inflammation, J. Immunol., 1998, $160,943-952$

[149] Longhi L., Ortolano F., Zanier E.R., Perego C., Stocchetti N.,De Simoni M.G., Effect of traumatic brain injury on cognitive function in mice lacking p55 and p75 tumor necrosis factor receptors, Acta Neurochir. Suppl., 2008, 102, 409-413

[150] McAfoose J., Koerner H.,Baune B.T., The effects of TNF deficiency on age-related cognitive performance, Psychoneuroendocrinology, 2009, 34, 615-619

[151] Akassoglou K., Probert L., Kontogeorgos G.,Kollias G., Astrocytespecific but not neuron-specific transmembrane TNF triggers inflammation and degeneration in the central nervous system of transgenic mice, J. Immunol., 1997, 158, 438-445

[152] Dean B., Tawadros N., Scarr E.,Gibbons A.S., Regionallyspecific changes in levels of tumour necrosis factor in the dorsolateral prefrontal cortex obtained postmortem from subjects with major depressive disorder, J. Affect. Disord., 2010, 120, 245-248

[153] Grassi-Oliveira R., Brietzke E., Pezzi J.C., Lopes R.P., Teixeira A.L.,Bauer M.E., Increased soluble tumor necrosis factor-alpha receptors in patients with major depressive disorder, Psychiatry Clin. Neurosci., $2009,63,202-208$ 